\title{
EDITORIAL
}

\section{Focus on analytical science in Spain (JAI 2008)}

\author{
Joan O. Grimalt • Alfredo Sanz-Medel
}

Published online: 26 May 2009

(C) Springer-Verlag 2009

Every 3 years Barcelona celebrates the EXPOQUIMIA, the largest chemical exhibition in southern Europe. On this occasion a major Conference on Instrumental Analysis (Jornadas de Análisis Instrumental, JAI) is held that takes advantage of the synergies generated by the simultaneous presence of scientists and technical staff working in analytical chemistry, commercial exhibitors of instrumentation, and companies whose main activities are related to chemistry.

From October 21 to October 23, 2008, JAI celebrated its 12th anniversary. It was organized by the Spanish Society of Chromatography and Related Techniques (SECyTA), the Society of Analytical Chemistry, the Society of Mass Spectrometry (SEEM), and Society of Proteomics and Optics, the Society of Applied Spectroscopy, and the Association of Environmental Sciences and Techniques. The conference was attended by 580 registered participants. A total of 444 communications were given, 71 in oral form and 373 as posters. A large proportion of these covered environmental applications (122) and food quality and safety (107). Others were related to developments in instrumental analysis (41), pharmaceutical products (21), clinical analysis (21), metal speciation (17), chemometrics

J. O. Grimalt $(\bowtie)$

Department of Environmental Chemistry, Institute of Environmental Assessment and Water Research (IDÆA-CSIC), Jordi Girona 18,

08034 Barcelona, Spain

e-mail: joan.grimalt@idaea.csic.es

A. Sanz-Medel

Department of Physical and Analytical Chemistry,

University of Oviedo,

c/Julián Clavería 8 ,

33006 Oviedo, Spain

e-mail: asm@uniovi.es and theoretical developments (12), nanotechnology (10), and several other topics.

In addition, interesting lectures were given by invited speakers such as Kurt Wüthrich, a Nobel laureate in chemistry (2002), from the Scripps Research Institute (La Jolla, California, USA) and the Institute of Molecular Biology and Biophysics (ETH Zürich, Switzerland), Yoshinobu Baba from the Plasma Nanotechnology Research Center of Nagoya University (Japan), Detlef Günther from the Institute of Inorganic Chemistry (ETH Zürich, Switzerland), Philip J. Marriott from the School of Applied Sciences of RMIT University (Melbourne, Australia), and Cameron McLeod from the Centre for Analytical Sciences of the University of Sheffield (UK).

Several awards were given to the participating students. There were 11 best poster prizes, some of them for specific subjects and others without topic restriction. As customary during previous JAI meetings, Analytical and Bioanalytical Chemistry was present and two $\mathrm{ABC}$ poster prizes (on bioanalytics and on chemical speciation) were awarded on behalf of the journal. There were also two awards for the two best oral communications in chromatography (awarded by SECyTA) and for the two best papers in mass spectrometry (awarded by SEEM).

The special issue is a collection of a few of the presentations given at the 12th JAI conference, devoted to instrumental analysis, for example, gas chromatographymass spectrometry (GC-MS) and liquid chromatographymass spectrometry (LC-MS) applications to determinations of trace organic compounds in environmental samples and technical formulas. Applications of GC-MS, LC-MS, and selective electrodes to the analysis of drugs and metabolites in human samples are covered. Studies of atomic fluorescence spectrometry for total determinations and speciation of hydride-forming elements in garlic still show continuing 
interest in trace element speciation analysis. The synergic selectivity afforded by the combination of room temperature phosphorescence detection and molecularly imprinted polymer recognition is described to develop a convenient carbaryl pesticide optical sensor. Finally, flowinjection analysis hyphenated with liquid-core waveguides was applied to develop cleaner analytical tools for water contamination. We hope that the readers of Analytical and Bioanalytical Chemistry will enjoy reading these contributions.

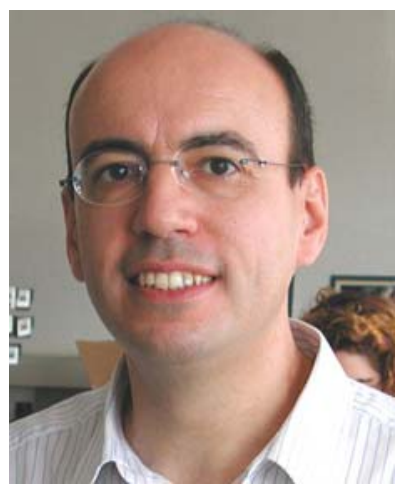

Joan O. Grimalt is Research Professor and Director of the Institute of Environmental Assessment and Water Research (IDÆA) of the Spanish Council for Scientific Research (CSIC). His professional activity has developed within environmental organic geochemistry. More specifically, his research is devoted to the study of the natural and anthropogenic organic compounds as markers of the health status of ecosystems and living organisms (including humans).

He has published about 460 scientific papers, most of them in international peer-reviewed journals. Presently, he is President of the Spanish Society of Chromatography and Related Techniques. He has received the King Jaume I award devoted to the preservation of environment (Valencian Autonomous Government, 2005), the Environment Award of the Catalan Academia (2001), and the Award of Scientific Research of the City of Barcelona (2000).

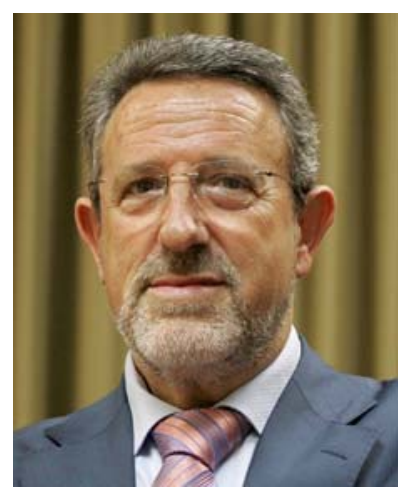

Alfredo Sanz-Medel has been Professor in the Department of Physical and Analytical Chemistry of Oviedo University (Spain) since 1982. He is author or coauthor of around 500 scientific publications in international journals, several patents, and books. His present research interests include new atomic detectors and ion sources for ultratrace analysis using plasmas, new molecular optical sensors, particularly those based on the use of quantum dots, as well as hybrid techniques, coupling a separation unit and an atomic detector, for ultratrace and trace metal speciation to solve biological and environmental problems and speciation for proteomics, integrating mass spectrometry (MS) "molecular" (matrix-assisted laser desorption/ionization and electrospray $\mathrm{MS}^{n}$ ) and "atomic" [inductively coupled plasma (ICP) MS] techniques and introducing the extensive use of ICP-MS to carry out "heteroatom-tagged proteomics," both for qualitative and for quantitative purposes. He has been an editor of Analytical and Bioanalytical Chemistry since 2002. At Euroanalysis 2007 in Antwerp he received the Robert Kellner Award. 